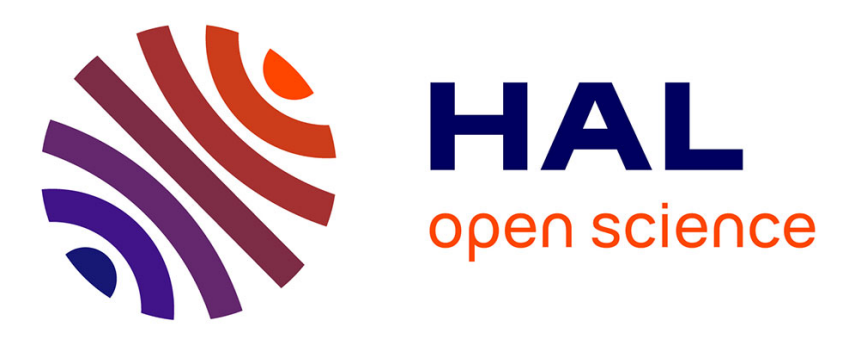

\title{
The Ictal Signature of Thalamus and Basal Ganglia in Focal Epilepsy
}

Francesca Pizzo, Nicolas Roehri, Bernard Giusiano, Stanislas Lagarde, Romain Carron, Didier Scavarda, Aileen Mcgonigal, Cristina Filipescu, Isabelle Lambert, Francesca Bonini, et al.

\section{To cite this version:}

Francesca Pizzo, Nicolas Roehri, Bernard Giusiano, Stanislas Lagarde, Romain Carron, et al.. The Ictal Signature of Thalamus and Basal Ganglia in Focal Epilepsy. Neurology, 2020, 96 (2), pp.e280 e293. 10.1212/wnl.0000000000011003 . hal-03500855

\section{HAL Id: hal-03500855 https://hal.science/hal-03500855}

Submitted on 22 Dec 2021

HAL is a multi-disciplinary open access archive for the deposit and dissemination of scientific research documents, whether they are published or not. The documents may come from teaching and research institutions in France or abroad, or from public or private research centers.
L'archive ouverte pluridisciplinaire HAL, est destinée au dépôt et à la diffusion de documents scientifiques de niveau recherche, publiés ou non, émanant des établissements d'enseignement et de recherche français ou étrangers, des laboratoires publics ou privés. 


\section{The ictal signature of thalamus and basal ganglia in focal epilepsy: An SEEG study}

Pizzo Francesca ${ }^{1}, \mathrm{MD}$ PhD, Roehri Nicolas ${ }^{2}, \mathrm{PhD}$, Giusiano Bernard ${ }^{2}, \mathrm{MD}$ PhD, Lagarde Stanislas ${ }^{1}$, MD, Carron Romain ${ }^{3}$, MD PhD, Scavarda Didier ${ }^{4}$, MD PhD, McGonigal Aileen ${ }^{1}$, MD PhD, Filipescu Cristina ${ }^{5}, \mathrm{MD}$, Lambert Isabelle ${ }^{1}, \mathrm{MD} \mathrm{PhD}$, Bonini Francesca ${ }^{1}, \mathrm{MD}$ PhD, Trebuchon Agnes ${ }^{1}, \mathrm{MD} \mathrm{PhD}$, Bénar Christian-George ${ }^{2 *}, \mathrm{PhD}$, Bartolomei Fabrice ${ }^{1^{*}}$ MD PhD.

Neurology® Published Ahead of Print articles have been peer reviewed and accepted for publication. This manuscript will be published in its final form after copyediting, page composition, and review of proofs. Errors that could affect the content may be corrected during these processes. 


\section{$\underline{\text { Affiliations : }}$}

1 Aix Marseille Univ, APHM, INSERM, INS, Inst Neurosci Syst, Timone Hospital, Epileptology Department, Marseille, France

2 Aix Marseille Univ, Inserm, INS, Institut de Neurosciences des Systèmes, Marseille

3 Aix Marseille Univ, APHM, INSERM, INS, Inst Neurosci Syst, Timone Hospital, Functional and Stereotactic Neurosurgery, Marseille, France

4 Aix Marseille Univ, APHM, INSERM, INS, Inst Neurosci Syst, Timone Hospital, Pediatric Neurosurgery, Marseille, France

5 GHU Paris, Psychiatrie et Neurosciences, St Anne, Paris

* Equally contributing

Corresponding authors: Dr Francesca Pizzo francesca.pizzo@ap-hm.fr, Prof. Fabrice Bartolomei fabrice.bartolomei@ap-hm.fr

Character count of title: 83

Abstract words: 241

Introduction words: 250

Body of the manuscript words: 3797

N figures: 6

N tables: 2

N references: 50

Statistical analysis: Roehri N., Giusiano B. 
Search terms: SEEG, thalamus, epilepsy surgery, caudate nucleus, epileptogenic networks

Study funding: This study has been carried out within the Federation Hospitalo-Universitaire (FHU) EPINEXT thanks to the support of the A*MIDEX project (ANR-11-IDEX-0001-02) funded by the "Investissements d'Avenir" French Government program managed by the French National Research Agency (ANR). We confirm that we have read the Journals position on issues involved in ethical publication and affirm that this report is consistent with those guidelines.

Disclosure: The authors report no disclosures relevant to the manuscript. 


\section{Abstract}

Objective: To determine the involvement of subcortical regions in human epilepsy by analyzing direct recordings from these regions during epileptic seizures using stereoelectroencephalography (SEEG) Methods: we studied the SEEG recordings of a large series of patients (74 patients, 157 seizures) with an electrode sampling the thalamus and in some cases also the basal ganglia (caudate nucleus -22 patients- and putamen -4 patients). We applied visual analysis and signal quantification methods (Epileptogenicity Index, EI) to their ictal recordings and compared electrophysiological with clinical data. Results: We found that in $86 \%$ of patients thalamus was involved during seizures (visual analysis) and that $20 \%$ showed high values of epileptogenicity $(\mathrm{EI}>0.3)$. Basal ganglia may also disclose high values of epileptogenicity ( $9 \%$ in caudate nucleus) but to a lesser degree than thalamus $(\mathrm{p}<0.01)$. We observed different seizure onset patterns including low voltage high frequency activities. We found high values of thalamic epileptogenicity in different epilepsy localisations, including opercular and motor epilepsies. We found no difference between epilepsy aetiologies (cryptogenic vs malformation of cortical development, $\mathrm{p}=0.77$ ). Thalamic epileptogenicity was correlated with the extension of epileptogenic networks $(\mathrm{p}=$ $0.03, \rho 0.32)$. We found a significant effect $(\mathrm{p}<0.05)$ of thalamic epileptogenicity regarding the post-surgical outcome (higher thalamic EI corresponding to higher probability of surgical failure) Conclusions: Thalamic involvement during seizures is common in different seizure types. The degree of thalamic epileptogenicity is a possible marker of the epileptogenic network extension and of post-surgical prognosis. 


\section{Introduction}

Focal epilepsy is traditionally considered as the epitome of a cortical disease. However Henri Gastaut in the 1970s discussed the idea of focal epilepsy as a cortico-subcortical disease, in which subcortical structures could be responsible for the seizures' initiation ${ }^{1}$. Even earlier, Jasper wrote about a "cortico-thalamic rhythmic system" that could be activated by a focal discharge. ${ }^{2}$ Still, the involvement of subcortical structures in the epileptic network was long ignored. The scant literature on intracerebral recordings, mainly on temporal lobe epilepsy, showed that subcortical structures, such as the thalamus ${ }^{3-6}$, caudate nucleus ${ }^{7}$ or other basal ganglia ${ }^{8}$ are involved in seizure dynamics. Studies from non-human primates also demonstrated the participation of subcortical nuclei in ictal networks ${ }^{9} 10,11$.

Recently, the role of subcortical structures in epilepsy gained renewed interest. Some neuroimaging studies ${ }^{12-17}$ evidenced the participation of the thalamus in epileptic networks suggesting that its involvement is related to post-surgical prognosis ${ }^{4,18}$. Moreover, subcortical-cortical connectivity was shown to be altered in different epilepsy types. ${ }^{19,20}$

When surgery is contraindicated or unsuccessful, deep brain stimulation (DBS) targeting thalamic nuclei can be an option (for a review see ${ }^{21}$ ) but the mechanisms of corticosubcortical interactions during seizures are mostly unknown and it is unclear which type of epilepsy is best suited to such a treatment.

The aims of this work were to evaluate thalamic and other subcortical nuclei participation in epileptogenic networks and to estimate the correlation of thalamic activity with clinical data and post-surgical outcome. 


\section{Methods}

\section{Patient selection}

We selected patients who underwent SEEG exploration from January 2001 to May 2018 and who had at least one intracranial electrode implanted in the thalamus. Some of the patients had also an electrode reaching other subcortical structures (caudate nucleus or putamen). At the time of the SEEG recording, all patients had a comprehensive evaluation including detailed clinical history, neurological examination, neuropsychological testing, routine MRI and surface electroencephalography (EEG). SEEG exploration was carried out during longterm video-EEG monitoring, as part of normal patient clinical care. Clinical data, SEEG recordings including recorded epileptic seizures were collected and analysed. The Engel class surgical outcome classification was used to assess post-surgical outcome.

\section{Standard Protocol Approvals, Registrations, and Patient Consents}

The institutional review board of the French Institute of Health (IRB15226) approved this study and a written patient consent was obtained from all included patients.

\section{SEEG recordings and montage selection}

Recordings were performed using intracerebral multiple contact electrodes (10-15 contacts, length: $2 \mathrm{~mm}$, diameter: $0.8 \mathrm{~mm}, 1.5 \mathrm{~mm}$ apart) placed intracerebrally according to Talairach's stereotactic method. The anatomical targeting of electrodes was established, independently of this study, in each patient according to information available after the non-invasive study and clinical hypotheses about the localization of the epileptogenic zone. The number of electrodes ranged from 6 to 22 electrodes, with more recent implantation having an higher number of electrodes. 
A post-operative computerized tomography (CT) scan and/or MRI were used to verify the absence of bleeding and the position of electrodes. Video-EEG recording was performed as long as necessary (1 to 3 weeks) to record several of the patient's habitual seizures. Finally, CT-scan/MRI data fusion was performed when all data were available to accurately check the anatomical location of each contact along the electrode trajectory. For this purpose we used our in-house software GARDEL - http://meg.univ-amu.fr/wiki/GARDEL:presentation - ${ }^{22}$. In patients explored before 2008, imaging data were in some cases lacking and we used the description of electrode position that was available for all patients. We included these patients since the aim of the study was to evaluate thalamic participation during seizures, while a detailed anatomical description of electrode position was beyond the scope of this study. An exploration of the thalamus targeting the pulvinar medialis has become customary in our department whenever a posterior temporal electrode exploring the planum temporale (PT) has to been implanted for the definition of the epileptogenic zone. Indeed, it is technically easy and safe to insert an orthogonally implanted electrode slightly deeper at the level of PT and thus reach the pulvinar medialis with the most medial contacts. A division between the thalamic contacts located in the pulvinar versus those not reaching the pulvinar, but other thalamic subnuclei (anterior, median and lateral), was computed. Regarding basal ganglia, the electrode used to explore the frontal operculum for clinical reasons was also sampling the head of the caudate nucleus. The putamen could also be explored by an opercular electrode or an oblique insular electrode.

Signals were recorded on a Natus system sampled at 256, 512 or $1024 \mathrm{~Hz}$ with 16 bits resolution. Two hardware filters were present in the acquisition procedure. The first is a highpass filter (cut-off frequency equal to $0.16 \mathrm{~Hz}$ ) used to remove very slow variations that could contaminate the baseline. The second is an anti-aliasing low-pass filter (cut-off frequency 
dependent on sampling frequency: equal to $97 \mathrm{~Hz}$ at $256 \mathrm{~Hz}, 170 \mathrm{~Hz}$ at $512 \mathrm{~Hz}$ and $340 \mathrm{~Hz}$ at $1024 \mathrm{~Hz})$.

In each patient, to analyse data, a SEEG bipolar montage was created and applied to all selected seizures. The SEEG montage included all subcortical channels, as well as all grey matter channels. Channels showing artefacts were excluded from analysis. All signal analysis was performed with the AnyWave software (available at http://meg.univamu.fr/wiki/AnyWave:Download ) ${ }^{23}$.

\section{Ictal recordings: visual analysis and computation of the Epileptogenicity Index (EI)}

Seizure were collected (with a maximum of 3 seizures per patient) and two types of analysis were done: visual and quantified.

Visual analysis was done with the help of normalized time frequency analysis (nTF) ${ }^{24}$. In particular, we characterised seizure onset patterns (SOP) ${ }^{25}$ in the thalamus and basal ganglia. The pattern in the subcortical structures was analysed only if it was present during the first 15 seconds from cortical seizure onset. Specific subcortical SOP were defined as low voltage fast activity (LVFA) associated or not with DC shift, rhythmic spikes or rhythmic spikes and wave discharges from alpha to higher frequency band (RS), and theta band discharge (theta). Discharges involving several frequency bands could be found in thalamus at the same time. In this case we selected the one with the highest normalised power as the main discharge. Discharges at other frequencies that were simultaneously present were also analysed. If a LVFA was present in any seizure for the patient, it was considered as the main pattern. With the RS pattern we included all patterns that did not show a clear fast discharge in the nTF but not even only a theta propagation pattern. Heterogeneous patterns could be recorded, ranging from spikes in the beta frequency to oscillations in the alpha band and a mixture of different activities. 
To perform quantified analysis, we computed the EI for all selected seizures by using our inhouse plugin ${ }^{26}$, implemented in the AnyWave software ${ }^{23}$. The EI is a method applied to SEEG signal aiming at quantifying the epileptogenicity of brain structures. The EI methodology has been described extensively in previous works ${ }^{27}$. Briefly, the EI allows to quantify the epileptogenicity of a brain region by considering both 1) the capacity of this region to generate fast activity at the beginning of the seizure, changing from the slower background activity preceding the seizure to faster frequencies and 2) the velocity of this change during the seizure course; in other words the time in which this change take place. High EI values (>0.3) are characteristic of regions in which we can record a fast epileptic discharge at the beginning of a seizure (generally the very firsts seconds).

When computation of EI was not possible, e.g. in absence of a fast discharge or fast spiking activity or in presence of a noisy signal, the patient was excluded from subsequent analysis. If the thalamus ipsilateral to the seizure onset side was not explored, the patient was excluded. Structures involved at seizure onset as detected by EI analysis were then compared to visual analysis to verify concordance between the two analyses. A value of EI for each sampled brain region was calculated, with a threshold of 0.3 to define a channel as epileptogenic ${ }^{27}$. The same threshold was used for other subcortical structures.

\section{Data analysis}

The number of patients and seizures with a high epileptogenicity in the thalamus or in another subcortical structure were calculated, as well as the number of patients showing an ictal discharge in the time course and nTF analysis. Values of thalamic epileptogenicity (one per patient - the maximum EI value across all seizures) were grouped according to clinical data as epilepsy aetiology and epilepsy type. 
The primary goal of this study was to examine the relationship between epileptogenicity of the thalamus and epilepsy severity. To answer this question, we first computed the Spearman correlation between thalamic epileptogenicity and i) number (or percentage) of brain regions with high epileptogenicity $(E I \geq 0.3$ ) and ii) epilepsy duration. Secondly, we investigated whether thalamic epileptogenicity is higher in patients with poor post-surgical outcome compared to those with good outcome (Engel class I and II vs Engel class III and IV) using a multivariate probit regression and taking the number of brain regions with $E I \geq 0.3$ and its interaction with thalamic epileptogenicity as control variables. For the regression, we used standardized variables (i.e. we transformed the variables so that the mean and standard deviation equal zero and one respectively) to handle more homogeneous variables. We finally controlled for multiple testing using the False-Discovery Rate procedure ${ }^{28}$; only adjusted pvalues are reported unless stated otherwise.

The secondary aim of this study is to describe the repartition in percentage of different clinical characteristics (i.e. aetiology, epilepsy type, seizure onset type) in this patient cohort, and the differences of i) epileptogenicity of the explored subcortical structures (thalamus, caudate nucleus, putamen) and ii) thalamic epileptogenicity between different groups of aetiology and type of epilepsy. The comparison was only done when a minimum of twelve observations were available per group. This number was arbitrarily chosen as the minimum amount to have meaningful statistics. We report the common language effect size of the Wilcoxon rank sum test (i.e. the $\mathrm{U}$ statistic divided by the product of the number of elements of each variable) and its 95-percent confidence interval ${ }^{29}$ for the comparison between different variables. The percentages and their 95-percent confidence intervals, calculated with continuity correction, are written when the number of elements is above five (minimum amount for the confidence interval validity). The statistical analysis was done using MATLAB (The Mathworks Inc., 
Natick, MA, U.S.A.), and the R-package asht for the confidence interval of the Wilcoxon rank sum test.

\section{Data Availability}

Full access to data is possible upon reasonable request.

\section{Results}

\section{Population characteristics}

In our cohort, a total of 83 patients had at least one electrode in a thalamic nucleus. Eight patients were excluded due to the impossibility of computing EI (absence of fast discharges (5) signal too noisy (3)). One patient was excluded because the thalamus was explored in the hemisphere contralateral to the seizure onset. Finally, 74 patients were included (43 women). Twenty-two patients had an electrode in the caudate nucleus and 4 had one electrode exploring the putamen. Mean age at SEEG recording was 30.5 (range 5-61 SD 12.9), mean epilepsy duration was 18.3 (range 4-33 SD 11.4) and mean age of epilepsy onset was 12.2 (range 4 months-28 SD 9.4). One hundred and fifty-seven seizures were analysed.

The aetiology was: $31(42 \%,[30-54 \%])$ cryptogenic, $22(30 \%,[19-41 \%])$ malformation of cortical development (MCD), 8 (11\%, [3-19\%]) hippocampal sclerosis, 4 infectious disease, 9 (12\%, [4-20\%]) other aetiologies (including 3 post-stroke, 3 tumour, 2 head trauma, 1 cavernoma). The epilepsy type was: 36 (49\%, [37-61\%]) temporal lobe epilepsy (TLE) (23 mesial TLE, 7 lateral TLE, 6 mesio-lateral TLE), 11 (15\%, [6-24\%]) bitemporal epilepsy, 10 (13\%, [5-22\%]) temporal plus epilepsy, 3 opercular epilepsy, 8 (11\%, [3-19\%]) epilepsy of motor-premotor system, $6(8 \%,[1.2-15 \%])$ posterior epilepsy. 
Thirty-nine patients (53\%, [41-65\%]) had subsequent surgery, among which eleven had a follow up $<12$ months $(15 \%$, [6.1-24\%]). The mean follow-up duration was 61 months (range 2-198 months).

Finally, 14/28 (50\%, [30-70\%]) had good surgical outcome (12 Engel I - 2 Engel II) and 14 (50\%, [30-70\%]) had poor outcome (9 Engel III, 5 Engel IV). Thirty-five (47\%, [35-59\%]) did not have surgery after SEEG. In 24 (32\%, [21-44\%]) surgery was contraindicated. The reasons of contraindication were a widespread network $(18-24 \%$, [14-35\%]) or overlap of the epileptogenic zone with eloquent cortices $(6-8 \%,[1.2-15 \%])$. Six patients are waiting for surgery $(8 \%,[1.2-15 \%])$, three had good response to thermocoagulation, one patient died, and one was lost to follow up/refused surgery.

\section{Seizure onset patterns in thalamus}

Visual analysis revealed that the thalamus participated in seizures in the great majority of patients (86 \% [77-95\%] in the first 15 seconds). Different and particular patterns were observed: low voltage fast activity (LVFA, $31 \%$, [20-42\%]), rhythmic spikes (RS, 38\%, [26$50 \%]$ ) or theta activity (theta, 18\%, [8.2-27\%]) possibly with some fast activities. The distribution of SOP across epilepsy type is illustrated in Fig. 1. The main frequency of thalamic discharge as calculated by nTF was $20 \mathrm{~Hz}$ (range: 4 - $160 \mathrm{~Hz}$ ). It should be noted that in 16 patients, other frequencies of ictal discharges accompanied the main one (mean 50 $\mathrm{Hz}$, range: 10 - $190 \mathrm{~Hz}$ ). In summary a total of 4 patients presented ictal discharges above 80 Hz. Some examples of thalamic discharges are illustrated in Fig. 2 (A-D).

\section{Basal ganglia can participate in seizure genesis and propagation}

High epileptogenicity values, as evaluated with quantified analysis (EI), were also recorded from caudate nucleus and putamen (Fig. 3). Twenty-two patients had an exploration of caudate nucleus $(\mathrm{CN})$ and in two patients it was included in the EZ according to EI values. 
Regarding putamen, this was sampled in four patients, being in one part of the EZ (Table 1). Regarding SOP, in CN we observed in 7 patients a pattern classified as $\mathrm{RS}$ characterized by a discharge around 8-10 Hz with intermingled spikes; in 3 patients we observed a LVFA pattern (Fig 1E), in 4 patients a theta discharge and in 7 patients no participation in the first 15 seconds of the seizure was observed. In the putamen we observed a RS pattern in 2 patients (Fig. 2f), in one patient a theta activity and in one patient no ictal activity.

\section{Epileptogenicity of thalamus and basal ganglia and correlation with clinical data}

In fifteen patients $(15 / 74,20 \%,[10-30 \%])$ the thalamus was included in the EZ in at least one seizure (21 seizures). The pulvinar was the explored nucleus in $42 / 74$ patients, location of the others contacts in the thalamus was in the median nuclei $(8 / 74)$, in the lateral nuclei $(16 / 74)$ and in 8 patients it was not possible to reconstruct it retrospectively. In two patients $(2 / 22)$ the caudate nucleus was included in the EZ as was the putamen in one patient (1/4) (Fig. 3). When comparing epileptogenicity in thalamus and caudate nucleus we found a large difference (Wilcoxon rank sum test: uncorrected $\mathrm{p}<0.01$, effect size: 0.259 [0.158 0.401]), with higher values in thalamus. Two examples of seizures with high subcortical epileptogenicity are reported in Fig. 4.1 (thalamus) and Fig. 4.2 (caudate nucleus). The relationship between thalamic epileptogenicity and different types of epilepsy and aetiology of epilepsy are shown in Fig. 5.

The highest values of thalamic epileptogenicity were found in infectious disorders and cryptogenic epilepsies. No difference was found in thalamic epileptogenicity across the more represented aetiologies as the confidence interval of the effect size is large and centred near 0.5 (crypto vs MCD, Wilcoxon rank sum test: uncorrected $\mathrm{p}=0.77$, effect size: $0.531[0.377$ 0.678]). As far as localisation/type is concerned, the highest thalamic epileptogenicity was found in opercular and bitemporal epilepsies, but no statistical analysis was possible due to 
the insufficient number of observations per group. A significant correlation was found between the extension of the epileptogenic network (\% brain region with EI $>0.3-\mathrm{p}=$ $0.0379, \rho=0.32[0.100 .52]$ - and number of regions with $E I>0.3-p=0.0195, \rho=0.27$ [0.044 0.47]) and thalamic epileptogenicity (Fig. 6). No significant correlation of thalamic epileptogenicity and epilepsy duration was found ( $\rho=-0.00020755,[-0.220 .22], p=0.9986$ ).

\section{Thalamic epileptogenicity and surgical outcome}

To compare thalamic epileptogenicity and surgical outcome we included patients with a follow up of more than 12 months (28: 14 Engel I or II). We found using the probit regression (Table 2$)$ a significant effect $(\mathrm{p}<0.05)$ of the thalamic epileptogenicity regarding the postsurgical outcome while controlling for the number of brain regions with high epileptogenicity and its interaction. In fact, the confidence interval of the coefficient of the extent of the SOZ is large and does not permit to draw any conclusion concerning its relationship with the outcome.

\section{Discussion}

The present results demonstrate, in a large cohort of patients, that the thalamus is involved in focal seizures in the vast majority of patients $(86 \%)$ according to visual analysis. In a subset of patients (20\%) the thalamus was involved early in seizure generation, as shown by a high value of epileptogenicity measured by a quantified ictal analysis (EI). EI evaluate the rapidity of a brain region to generate fast activity at the beginning of the seizure, and thus indicates that a given region is involved at the very start of the seizure. We found a significant correlation between the number of regions with a high degree of epileptogenicity and thalamic epileptogenicity. We also showed that thalamic epileptogenicity has a significant effect regarding the post-surgical outcome. Taken together, these findings suggest that thalamic 
involvement in focal seizures could be a marker of extension of the epileptogenic network and may influence the surgical outcome.

Past research has mainly focused on thalamus in mesial temporal lobe epilepsy. According to Rosenberg and colleagues ${ }^{3}$ and Guye and colleagues ${ }^{4}$ a large percentage of MTLE showed thalamic involvement $(80 \%)$, with an effect on clinical presentation if thalamus was involved 4. Regarding seizure onset patterns, we found similar patterns to those described by Rosenberg, especially a prevalence of RS in MTLE (Fig. 1), but we also observed high frequency discharges in some cases, reaching a maximum of $190 \mathrm{~Hz}$

Here we showed that thalamic involvement is possible in all focal epilepsies independently of the lobar localisation or aetiology (Fig. 5). The possible connections of the different thalamic nuclei with the neocortex are reported in some tractography studies ${ }^{30,31}$. The pulvinar is reported to be extensively connected to large parts of the cortex from the mesial temporal lobe to the parietal cortex. Interestingly, a resting state functional connectivity study proposed pulvinar nuclei as a key reflection of symptom-related functional deficits in mTLE $^{32}$ and evidenced a connectivity of this nucleus with the orbitofrontal region. In our cohort, we found the highest values of thalamic epileptogenicity in bitemporal, insulo-opercular and motor system epilepsies. The high thalamic epileptogenicity in insulo-opercular epilepsy seems consistent with SEEG cortical evoked potentials, reported in Rosenberg's study ${ }^{33}$, in which these two regions appeared highly connected (90\% response rate) and with recent data on MRI insulo-thalamic connectivity ${ }^{34}$. Regarding motor-premotor epilepsy and thalamic epileptogenicity, the relationship is intriguing and could be related to the "higher order connections" of the pulvinar ${ }^{35}$. Patients with motor-premotor and insulo-opercular (in the dominant hemisphere) epilepsies are often contraindicated for surgery because of functional reasons. Recent data from our group ${ }^{36}$ demonstrated that pulvinar stimulation could be efficient in improving seizure termination and could potentially reduce degree of impaired 
consciousness. In this context our results suggest that DBS targeting the pulvinar could be an interesting option in some cases. Nevertheless, because of the limited number of patients with these epilepsies in our cohort, these data should be considered as preliminary observations and need to be confirmed by future studies.

Thalamic involvement in our study correlated with network extension. More complex epilepsies seem to more frequently involve thalamic participation in their epileptogenic network. Nevertheless, calculating network extension in patients with different SEEG implantations (number of electrodes) and different surgery outcome or contraindication to surgery (considering that some important brain regions could have missed in the implantation scheme) represent a limitation of the study.

Thalamic epileptogenicity was found to have a significant effect regarding seizure outcome, confirming the prognostic value of thalamic implication. Our results are in agreement with recent fMRI connectivity data showing that patients with TLE who showed higher presurgical levels of functional synchronization between the thalamus and other extratemporal regions had less favourable surgical outcome ${ }^{18}$. Thalamic involvement could also be a possible marker of the "synchronisability" of the network, and thus related to surgical outcome ${ }^{4,37}$.

Regarding basal ganglia, namely caudate nucleus and putamen, we found that they could also be involved in focal seizures as already reported with neurophysiological ${ }^{38}$ and MRI data ${ }^{39}$. In our cohort caudate nucleus showed high epileptogenicity in only $9 \%(2 / 22)$ of patients compared to the $20 \%(15 / 74)$ with high thalamic epileptogenicity and when comparing EI values on both structures we found a significant difference. However it could be possible that in a different cohort of patients, for example with a higher number of patients affected by frontal lobe epilepsies, caudate nucleus involvement would be more frequent ${ }^{10,11}$. Previous work on temporal lobe epilepsy showed a minor role of basal ganglia in the seizure network 
${ }^{40}$. Recently, cortico-striatal synchronisation was reported using SEEG $^{7}$ during focal seizures, especially at the end of seizures, supporting a role of these nuclei in seizure termination as previously reported by our group regarding thalamus ${ }^{6}$. A hypothesis about a role in inhibiting seizure spread was also proposed by other authors ${ }^{40}$ : according to this theory basal ganglia may influence cortical oscillatory processes related to control of seizures via their feedback pathways to the cortex.

Recently, indications for intracranial presurgical investigation including SEEG have been evolving, tending to include more "complex network" epilepsies and/or MRI-negative epilepsies $^{41}$. Wider SEEG indications are also related to the possibility of proposing palliative options in complex extended cases based on SEEG-guided radiofrequency thermocoagulation 42,43. Moreover, SEEG has been revealed to be useful in epilepsies with widespread networks related to post-stroke aetiology, in order to guide surgical disconnection ${ }^{44}$. Finally, some genetic epilepsies, as the case of tuberous sclerosis complex epilepsies, could also benefit from intracerebral explorations ${ }^{45}$. Actually in a large percentage of patients $(24 / 7439 \%$ in our cohort and 69/246 $28 \%$ in the Cuello et al. study ${ }^{46}$ ) surgery was contraindicated, evidencing an important need for other therapeutic options.

Our results indicate that the vision of "focal" epilepsy should change. In addition to the important notion of an epileptogenic network ${ }^{47,48}$, we showed that epilepsies are corticalsubcortical diseases in which epileptogenicity can affect subcortical structures, particularly the thalamus. In the future, therapies aimed at modifying network activity on a personalized scale will have to take these modifications into account. In this sense, the development of effective thalamus stimulation paradigms in DBS aimed at desynchronizing the network ${ }^{5}$ or elective modulation techniques of certain nodes through new simulation ${ }^{49,50}$ offer particularly encouraging prospects. 
Fig. 1: Percentage of different SOP in thalamus across epilepsy type.

Legend: biT - bitemporal epilepsy; T plus -temporal plus epilepsy; TLE,MTLE - mesio temporal lobe; TLE,MLTLE - mesio-lateral temporal lobe epilepsy; epilepsy TLE,LTLE lateral temporal lobe epilepsy; PE- posterior epilepsy; Op - insulo-opercular epilepsy; Mot motor-premotor epilepsy.

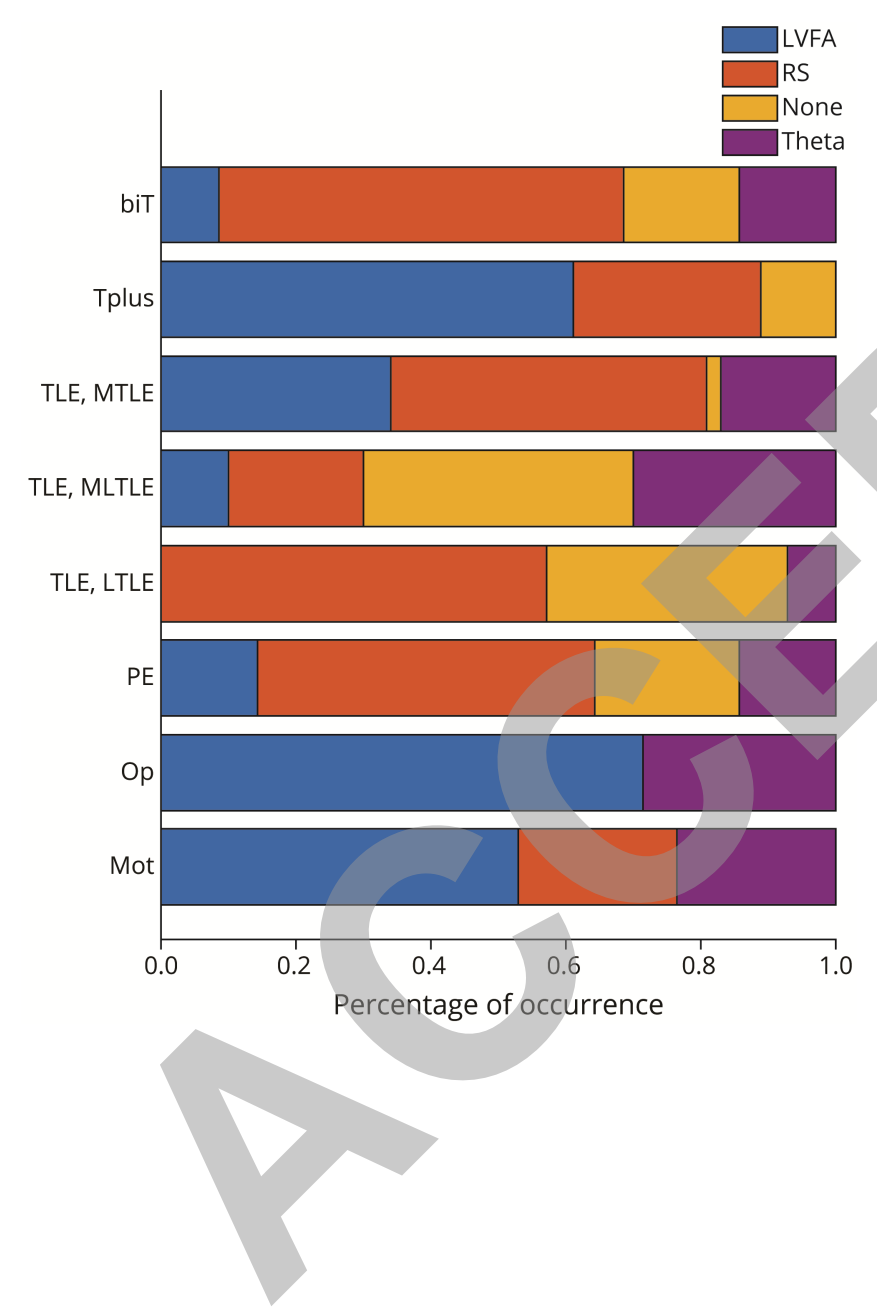


Fig. 2: Examples of subcortical ictal discharges represented in their time course and nTF analysis. In the thalamus: LVFA pattern (A and B), RS (C) and theta (D). Different frequencies may be present in each pattern. In $\mathrm{D}$, a high frequency component is visible, without a clear discharge (D). SOP in the caudate nucleus $(\mathrm{E})$ and in the putamen $(\mathrm{F})$.
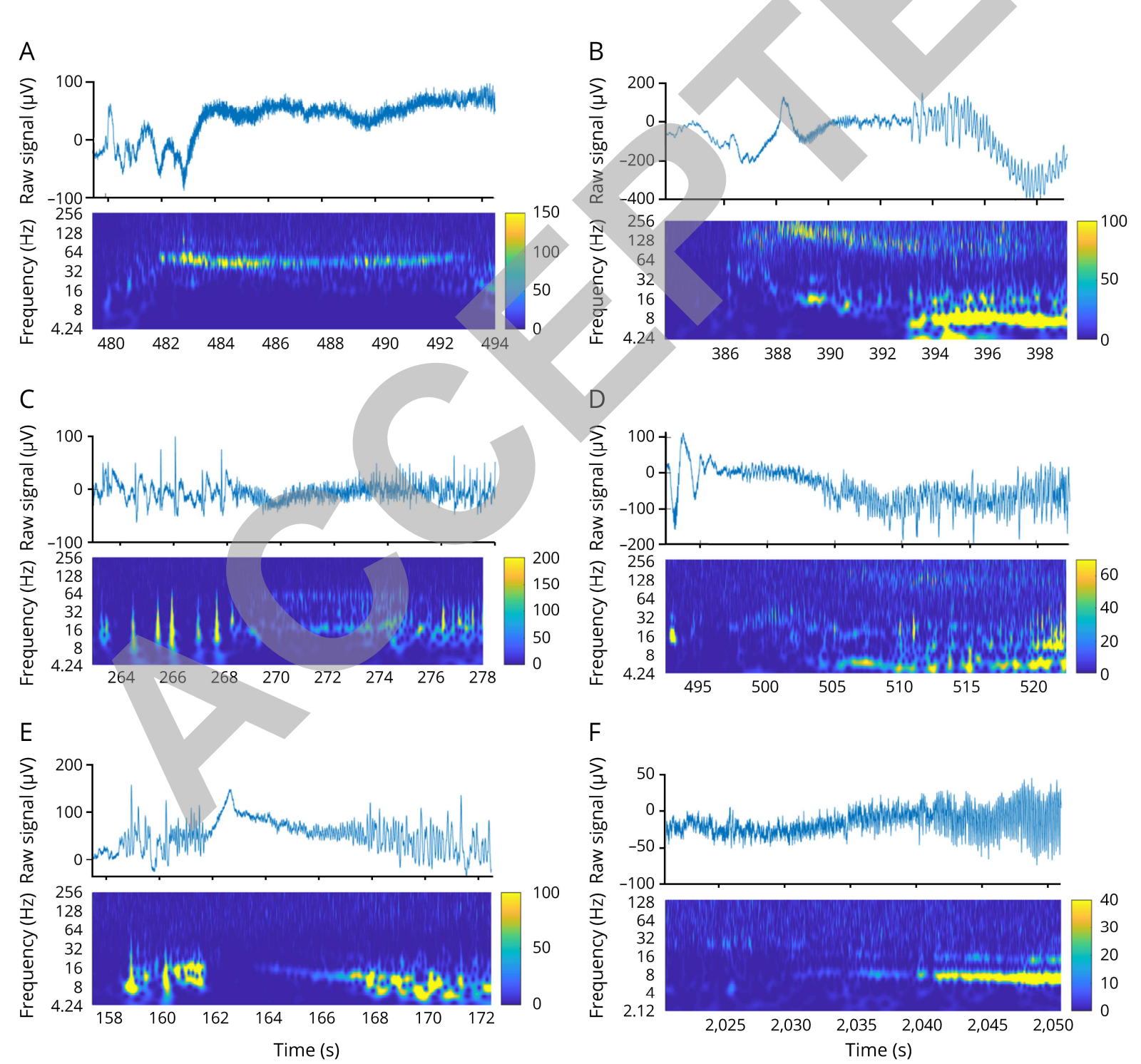
Fig. 3: EI values (max EI value per patient) in the different subcortical structures. (Thalamus vs Caudate nucleus Wilcoxon rank sum test $\mathrm{p}<0.01$ )

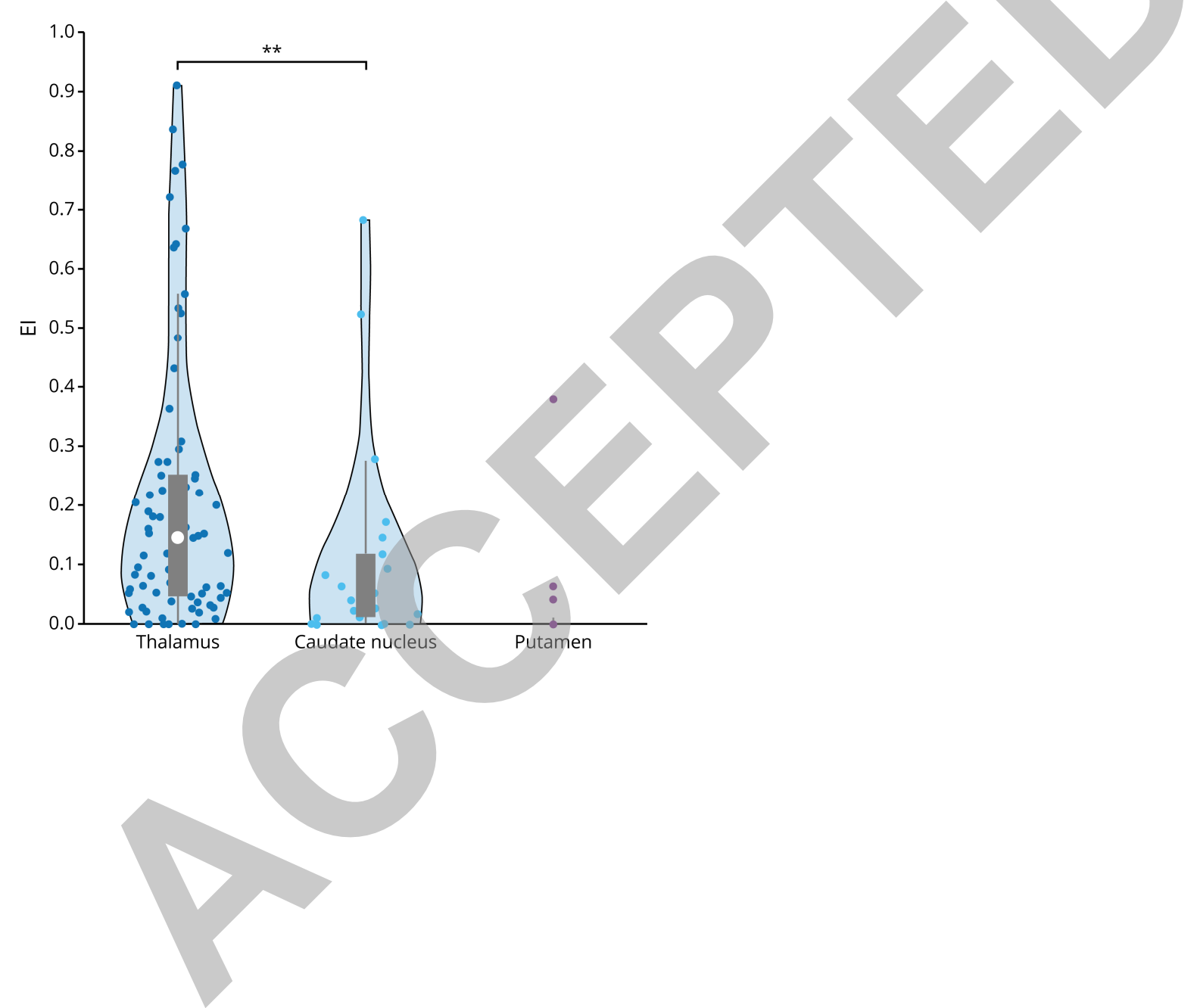


Fig. 4: Focal seizures involving thalamus (4.1, patient 64) and caudate nucleus (4.2, patient 52) a. SEEG at seizure onset: large epileptogenic network; note the fast discharge in thalamus (Th, 1a) and caudate nucleus $(\mathrm{CN}, 2 \mathrm{a}) \mathrm{b}$. Epileptogenicity Index map showing the increase in energy ratio (in blue to yellow scale) and the time of detection (circle - alarm time- and cross - detection time $<$ sup $>27</$ sup $>$ ) ${ }^{27}$ in each selected SEEG channel. Notably in the map of fig 4.1 a detection cross at the level of channel Th (thalamus) is evident at the very beginning of the seizure given rise to the high epileptogenicity value in thalamus. To be noted, the first detection (cross) is not at Th level but in the OC channel that show the maximum value of EI (as shown in c). Comparatively, in fig 4.2 an early cross is visible in the $\mathrm{CN}$ (caudate nucleus) but the maximum of energy ratio is evident at the level of OR that shows the highest EI value (shown in c). c. Results of the epileptogenicity index (in blue normalized EI, in red summed energy ratio) ${ }^{27}$ d. 3 D representation of the SEEG exploration; the balloons indicate the EI detections. Balloon colour (from yellow to red) and dimension correspond to the EI value e. MRI (T1 sequence) - CT data fusion: to be noted electrode H (see flash) sampling from thalamus (1e) and electrode OF' (see flash) sampling from caudate nucleus $(2 \mathrm{e})$

Legend: aCG- anterior cingulated cortex; aIns -anterior insula ; BT-basotemporal; Hiphippocampus; Ins- insula; L- left; mIns- middle insula; OC- central operculum; OF - frontal operculum; OP- parietal operculum; OR- orbitofrontal cortex; pCG- posterior cingulated gyrus; pIns- posterior insula; R-right; Th - thalamus; T lat - temporo-lateral 
A.a

R

R

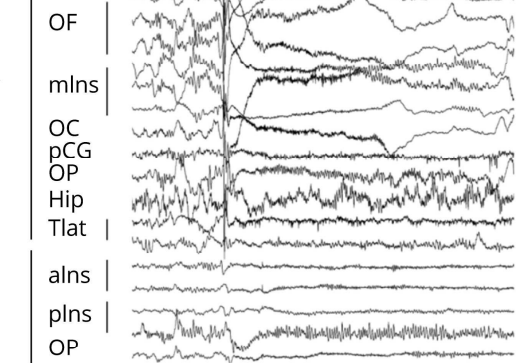
-1s
A.b
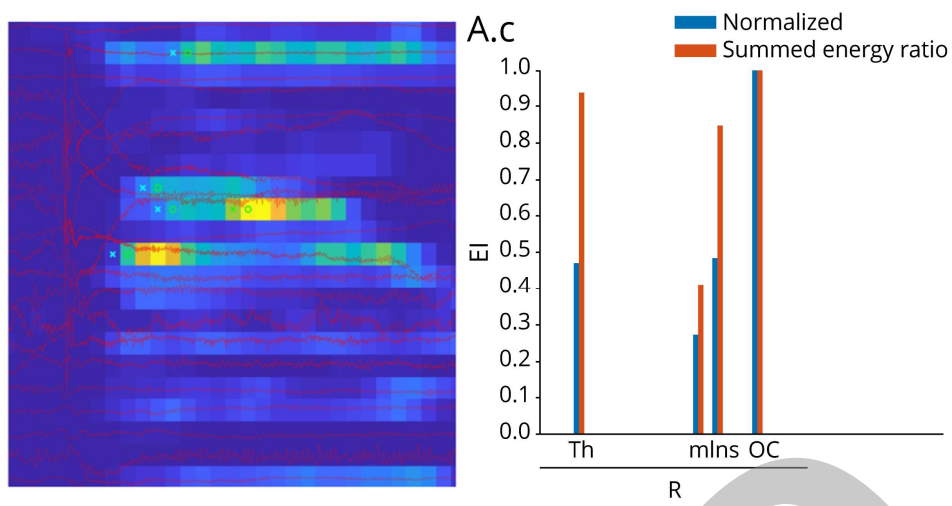

A.e

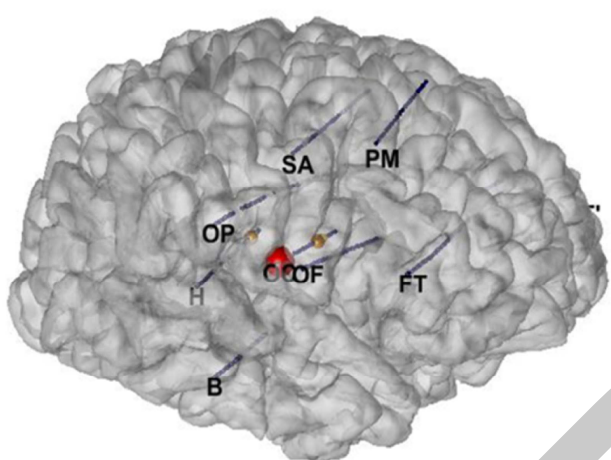

B.b

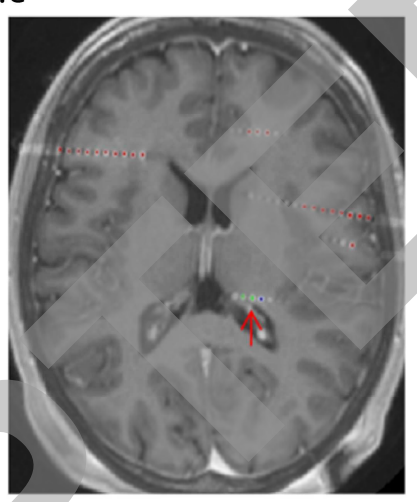

B.a

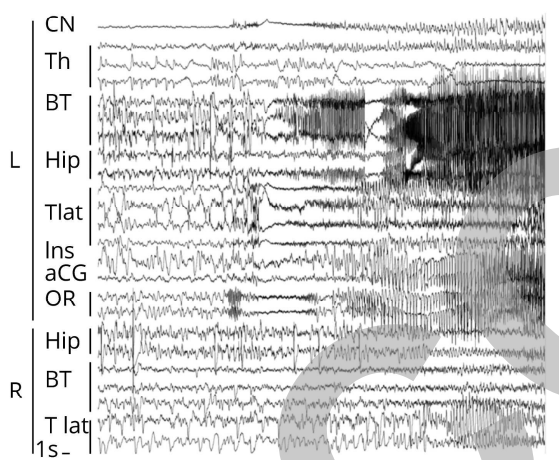

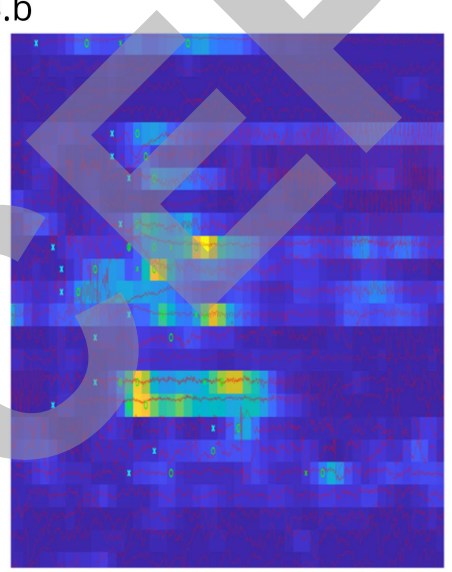

B.C

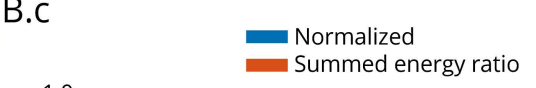

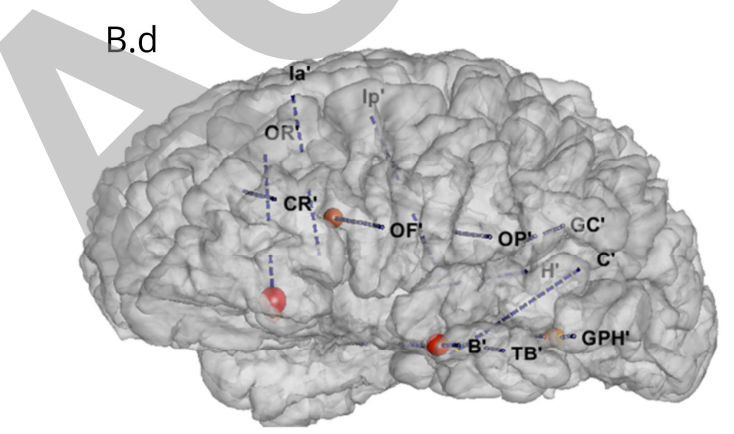

B.e

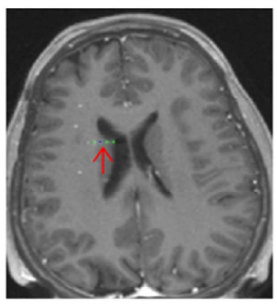


Fig. 5: Thalamic epileptogenicity across different epilepsy type and aetiologies. Each point represents the maximum EI value in the thalamus for each patient according to the type of epilepsy and aetiologies respectively (crypto vs MCD, Wilcoxon rank sum test: uncorrected $p=0.77$, effect size: $0.531[0.3770 .678]$ ).

Legend: Mot - motor-premotor epilepsy; Op - insulo-opercular epilepsy; PE- posterior epilepsy; TLE,LTLE - lateral temporal lobe epilepsy; TLE,MLTLE - mesio-lateral temporal lobe epilepsy; TLE,MTLE - mesio temporal lobe epilepsy; T plus -temporal plus epilepsy; biT - bitemporal epilepsy; HS - hippocampal sclerosis; Inf - post -infectious; MCDmalformation of cortical development; crypto - cryptogenic; other includes: cavernoma, post stroke epilepsy, post-traumatic epilepsy

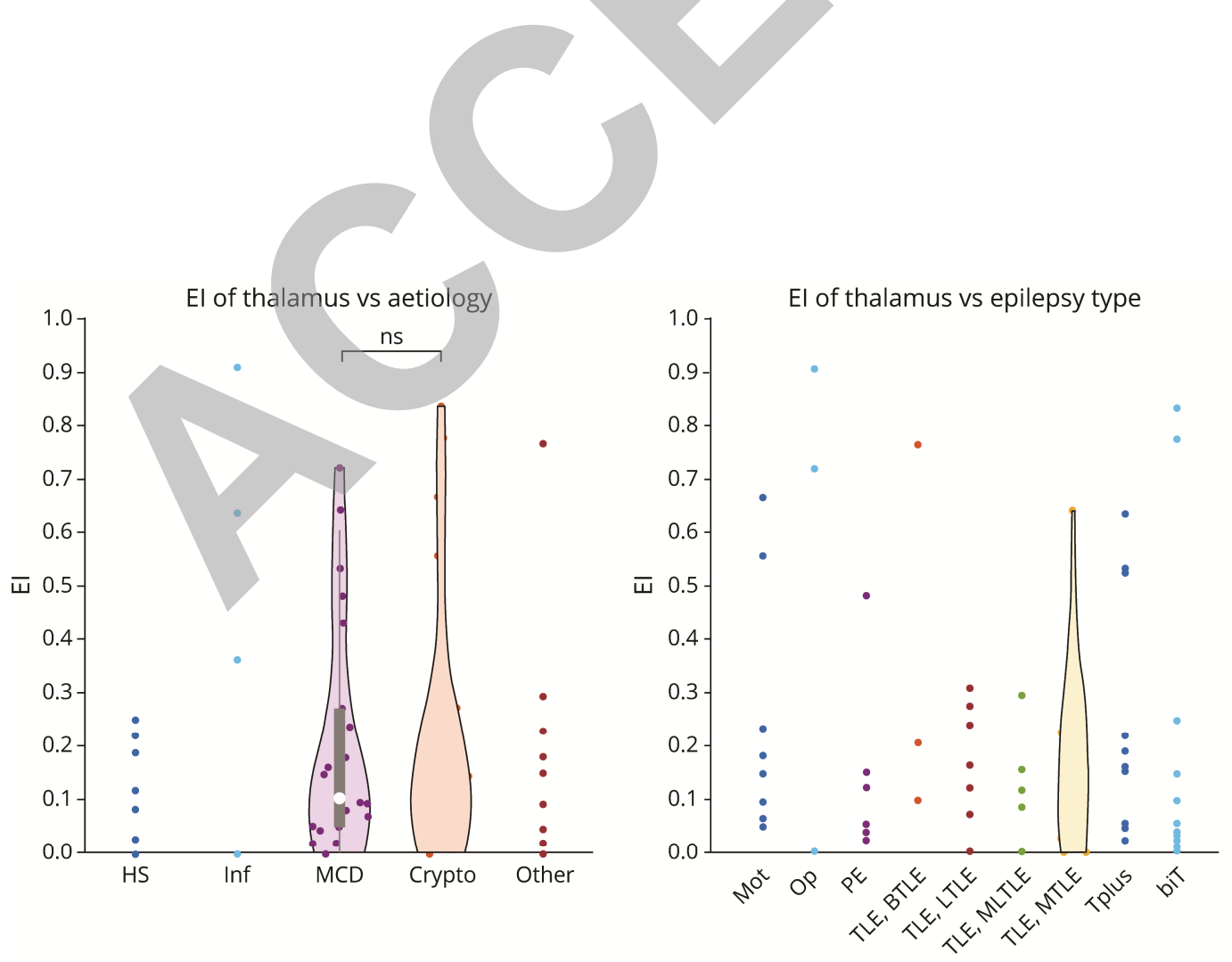


Fig. 6: Thalamic EI values correlation with the percentage of brain regions with a high EI value. A significant correlation was found $(\mathrm{p}=0.03, \rho 0.32)$ suggesting the thalamus as a possible marker of the extension of the epileptogenic network

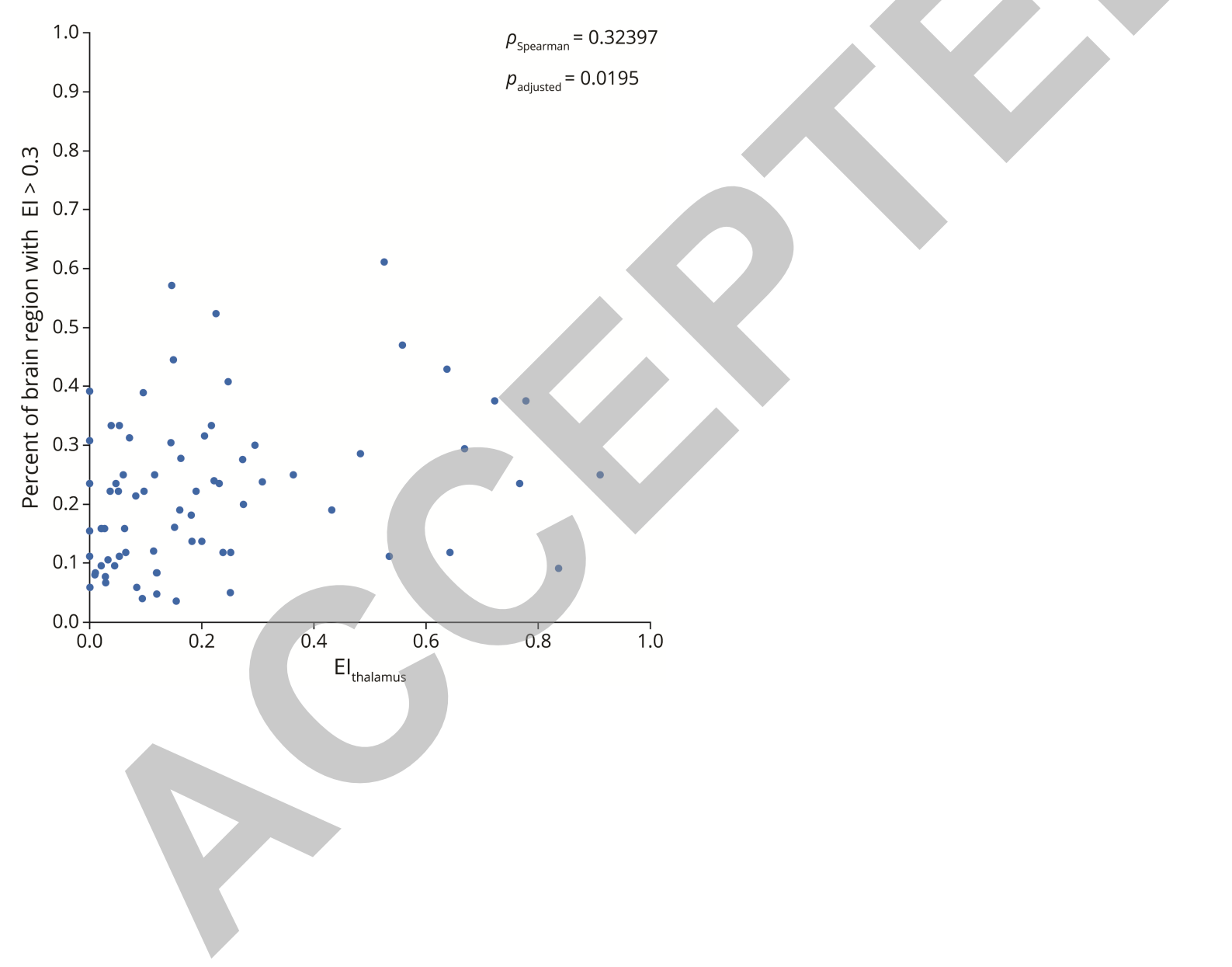


Table 1: Patient characteristics

\begin{tabular}{|c|c|c|c|c|c|c|c|c|c|c|c|c|}
\hline $\mathbf{n}$ & sex & $\begin{array}{l}\text { age at } \\
\text { SEE } \\
\text { G }\end{array}$ & $\begin{array}{l}\text { n of } \\
\text { seizures }\end{array}$ & epilepsy type & aetiology & SOP in $\mathrm{TH}$ & $\begin{array}{l}\text { other } \\
\text { subcortica } \\
\text { I/SOP }\end{array}$ & $\begin{array}{l}\text { epilepsy } \\
\text { onset }\end{array}$ & $\begin{array}{l}\text { du } \\
\text { rat } \\
\text { ion }\end{array}$ & $\begin{array}{l}\text { after SEEG: type of } \\
\text { surgery/contraindica } \\
\text { reason }\end{array}$ & $\begin{array}{l}\text { En } \\
\text { gel } \\
\text { cla } \\
\text { ss }\end{array}$ & $\begin{array}{l}\text { follow u } \\
\text { (months }\end{array}$ \\
\hline 1 & M & 15 & 2 & TLE, MLTLE & MCD & rTheta & & 6 & 9 & L T lobectomy & 3 & 198 \\
\hline 2 & $\mathrm{~F}$ & 44 & 1 & TLE, MTLE & HS & none & & 8 & 36 & L T lobectomy & 1 & 144 \\
\hline 3 & M & 37 & 2 & Mot & post stroke & rTheta & & 23 & & LF cortectomy & 2 & 46 \\
\hline 4 & M & 43 & 2 & Tplus & MCD & RSW & & 25 & 1 & R T lobectomy & 3 & 120 \\
\hline 5 & M & 24 & 1 & TLE, MTLE & tumor & LVFA & CN: LVFA & 1 & 23 & lesionectomy & 4 & 195 \\
\hline 6 & M & 43 & 2 & TLE, LTLE & crypto & RSW & $\mathrm{CN}: 1$ & 10 & 33 & $\mathrm{R}$ latero- $\mathrm{T}$ cortectomy & 1 & 72 \\
\hline 7 & $\mathrm{~F}$ & 17 & 3 & Mot & MCD & RSW & & 0 & 17 & L F cortectomy & 3 & 132 \\
\hline 8 & M & 22 & 2 & biT & tumor & RSW & & 16 & 6 & R T lobectomy & 1 & 168 \\
\hline 9 & M & 22 & 1 & TLE, LTLE & MCD & none & & 15 & 7 & R STG cortectomy & 1 & 120 \\
\hline 10 & $\mathrm{~F}$ & 35 & 2 & TLE, MLTLE & HS & none & $\mathrm{CN}$ : none & 1 & 34 & R T lobectomy & 1 & 36 \\
\hline 11 & M & 32 & 2 & biT & crypto & RSW & & 18 & 14 & C: bilateral & & \\
\hline 12 & $\mathrm{~F}$ & 35 & 1 & TLE, MLTLE & tumor & LVFA & & 3 & 32 & R Tl lobectomy & 2 & 132 \\
\hline 13 & M & 31 & 2 & TLE, MTLE & HS & LVFA & $\mathrm{CN}$ : none & 4 & 27 & L T lobectomy & 3 & 72 \\
\hline 14 & $\mathrm{~F}$ & 54 & 3 & TLE, MTLE & $\operatorname{Inf}$ & LVFA & & 1 & 53 & L T lobectomy & 3 & 42 \\
\hline 15 & $\mathrm{~F}$ & 13 & 3 & TLE, MTLE & HS & RSW & & 2 & 11 & L T lobectomy & 1 & 42 \\
\hline
\end{tabular}




\begin{tabular}{|c|c|c|c|c|c|c|c|c|c|c|c|c|}
\hline 16 & M & 25 & 2 & $\mathrm{Op}$ & Inf & rTheta & & 15 & 10 & OP gamma knife & 3 & 24 \\
\hline 17 & $\mathrm{~F}$ & 61 & 2 & TLE, MLTLE & crypto & RSW & & 28 & 33 & R T lobectomy & 3 & 36 \\
\hline 18 & F & 45 & 3 & PE & crypto & none & & 16 & 29 & C: bilateral & & \\
\hline 19 & M & 42 & 1 & TLE, MTLE & $\mathrm{HS}$ & rTheta & & 6 & 36 & R T lobectomy & & \\
\hline 20 & $\mathrm{~F}$ & 16 & 1 & TLE, LTLE & MCD & rTheta & & 13 & 3 & C: function & & \\
\hline 21 & $\mathrm{~F}$ & 46 & 3 & biT & crypto & none & & 12 & 34 & C: bilateral & & \\
\hline 22 & $\mathrm{~F}$ & 26 & 2 & PE & crypto & LVFA & $\mathrm{CN}$ : none & 7 & 19 & L TO cortect & & 132 \\
\hline 23 & M & 15 & 3 & PE & MCD & RSW & $\mathrm{CN}$ : none & 4 & 11 & & 4 & 150 \\
\hline 24 & $\mathrm{~F}$ & 19 & 2 & Tplus & MCD & RSW & & 12 & 7 & C: function & & \\
\hline 25 & $\mathrm{~F}$ & 48 & 2 & biT & crypto & RSW & & 14 & & & & \\
\hline 26 & M & 29 & 3 & Mot & crypto & LVFA & & 5 & & & & \\
\hline 27 & $\mathrm{~F}$ & 15 & 3 & TLE, LTLE & MCD & RSW & & 11 & & ectomy & 1 & 94 \\
\hline 28 & $\mathrm{~F}$ & 16 & 1 & Mot & post stroke & RSW & & & & & & \\
\hline 29 & $\mathrm{~F}$ & 27 & 2 & TLE, MTLE & crypto & RSW & $\begin{array}{l}\text { Put: RSW } \\
\text { CN: }\end{array}$ & 17 & 10 & R T lobectomy & 1 & 18 \\
\hline 30 & M & 12 & 3 & Op & MCD & LVFA & Put: RSW & 6 & 6 & thalamic stimulation & 4 & 140 \\
\hline 31 & $\mathrm{~F}$ & 25 & 2 & PE & MCD & RSW & & 5 & 20 & TO disconnection & 3 & 19 \\
\hline 32 & M & 28 & 1 & TLE, MTLE & MCD & LVFA & & 10 & 18 & C: function & & \\
\hline 33 & $\mathrm{~F}$ & 30 & 3 & biT & MCD & RSW & & 21 & 9 & C: bilateral & & \\
\hline 34 & M & 52 & 1 & TLE, MTLE & crypto & LVFA & CN: RSW & 35 & 17 & dead & & \\
\hline 35 & M & 19 & 2 & Tplus & crypto & LVFA & $\mathrm{CN}$ : RSW & 10 & 9 & C: extended & & \\
\hline 36 & $\mathrm{~F}$ & 22 & 1 & Tplus & crypto & RSW & & 18 & 4 & RT lobectomy, after VNS & 4 & 41 \\
\hline 37 & $\mathrm{~F}$ & 39 & 3 & TLE, MTLE & crypto & LVFA & & 20 & 19 & C: function & & \\
\hline
\end{tabular}




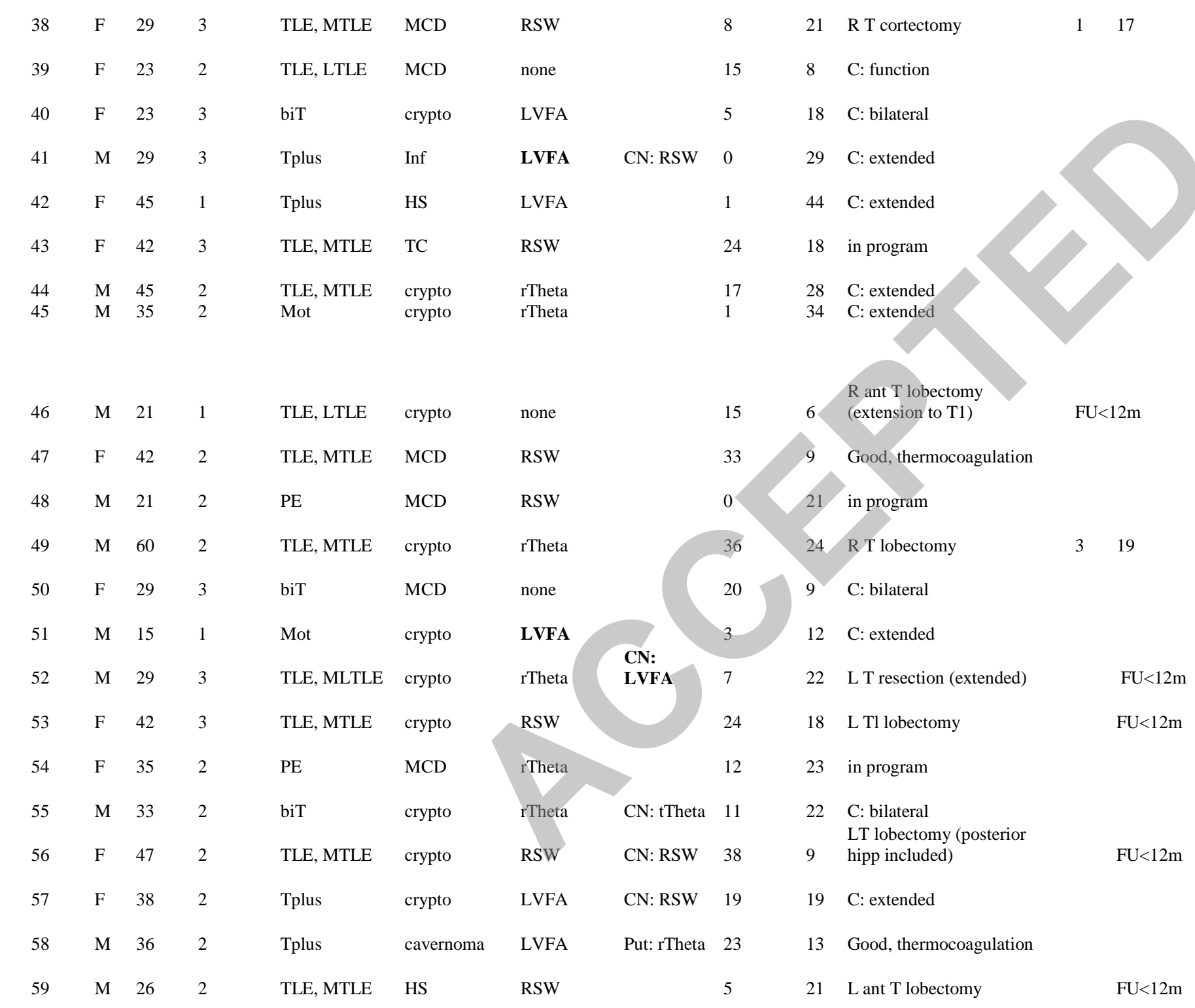




\begin{tabular}{|c|c|c|c|c|c|c|c|c|c|c|c|c|}
\hline 60 & $\mathrm{~F}$ & 25 & 2 & TLE, MLTLE & crypto & none & $\begin{array}{l}\mathrm{CN} \text { and } \\
\text { Put: none }\end{array}$ & 11 & 14 & in program & & \\
\hline 61 & M & 10 & 3 & TLE, MTLE & crypto & rTheta & & 3 & 7 & L T lobectomy & 1 & 18 \\
\hline 62 & M & 7 & 3 & TLE, MTLE & MCD & RSW & & 1,5 & 6 & LT lobectomy & & $\mathrm{FU}<12 \mathrm{~m}$ \\
\hline 63 & $\mathrm{~F}$ & 26 & 3 & TLE, MTLE & MCD & LVFA & & 23 & 3 & lesionectomy plus parahipp & & \\
\hline 64 & $\mathrm{~F}$ & 38 & 2 & Op & $\operatorname{Inf}$ & LVFA & CN: none & 3 & 35 & C: bilateral & & \\
\hline 65 & $\mathrm{~F}$ & 17 & 3 & Mot & crypto & LVFA & & 15 & 2 & C: function & & \\
\hline 66 & $\mathrm{~F}$ & 22 & 3 & TLE, LTLE & crypto & RSW & & 13 & 9 & tomy & & \\
\hline 67 & $\mathrm{~F}$ & 7 & 2 & Mot & post stroke & LVFA & & 2 & 5 & L F lobectomy, S & & $\mathrm{FU}<12 \mathrm{~m}$ \\
\hline 68 & M & 47 & 1 & Tplus & $\mathrm{TC}$ & LVFA & $\mathrm{CN}$ : rTheta & 22 & 25 & RT lobectomy & & $\mathrm{FU}<12 \mathrm{~m}$ \\
\hline 69 & $\mathrm{~F}$ & 20 & 1 & TLE, MTLE & HS & RSW & & 8 & & & & \\
\hline 70 & $\mathrm{~F}$ & 48 & 2 & TLE, MTLE & MCD & LVFA & CN: RSW & 11 & & Good, thermocoagulation & & \\
\hline 71 & $\mathrm{~F}$ & 37 & 3 & biT & crypto & RSW & & 21 & & C: bilateral & & \\
\hline 72 & $\mathrm{~F}$ & 32 & 1 & biT & crypto & rTheta & CN: rTheta & 24 & & RT lobectomy & & $\mathrm{FU}<12 \mathrm{~m}$ \\
\hline 73 & $\mathrm{~F}$ & 48 & 2 & Tplus & MCD & none & CN: none & 8 & 40 & in program & & \\
\hline 74 & M & 5 & 3 & biT & crypto & RSW & & 0 & 5 & R T lobectomy & & $\mathrm{FU}<12 \mathrm{~m}$ \\
\hline
\end{tabular}

Legend: F - female; M male; Mot - motor-premotor epilepsy; Op - insulo-opercular epilepsy; PE- posterior epilepsy; TLE,LTLE - lateral temporal lobe epilepsy; TLE,MLTLE - mesio-lateral temporal lobe epilepsy; TLE,MTLE - mesio temporal lobe epilepsy; T plus -temporal plus epilepsy; biT - bitemporal epilepsy. HS - hippocampal sclerosis; Inf - post -infectious; MCD- malformation of cortical development; crypto cryptogenic; other includes: cavernoma, post stroke epilepsy, post-traumatic epilepsy. RS- rhythmic spikes; LVF- low voltage fast activity; R right; L - left; T- temporal, F - frontal, ant- anterior, STG- superior temporal gyrus; SMA- supplementary motor area. C- contraindication.

In bold values of EI $>0.3$ for subcortical structures. 
Table 2: Multivariate probit regression

\begin{tabular}{|l|l|l|l|l|}
\hline \multirow{2}{*}{} & \multirow{2}{*}{ Coefficient estimate } & \multicolumn{2}{|l|}{$95 \%$ - confidence interval of the coefficient } & Adjusted p-value \\
\cline { 3 - 4 } & & Lower bound & Upper bound & \\
\hline Constant & 0.126 & -0.422 & 0.675 & NA \\
\hline Thalamic EI & 0.682 & 0.0520 & 1.312 & $0.0451^{*}$ \\
\hline $\begin{array}{l}\text { Number of regions } \\
\text { with EI > 0.3 }\end{array}$ & 0.602 & -0.124 & 1.328 & NA \\
\hline Interactions & -0.423 & & & NA \\
\hline
\end{tabular}

\section{Appendix 1: Authors}

\begin{tabular}{|c|c|c|}
\hline Francesca Pizzo & $\begin{array}{l}\text { Aix Marseille Univ, APHM, } \\
\text { INSERM, INS, Inst Neurosci Syst, } \\
\text { Timone Hospital, Epileptology } \\
\text { Department, Marseille, France }\end{array}$ & $\begin{array}{l}\text { conception and design of the study } \\
\text { acquired and analysed the data } \\
\text { drafted the manuscript and the figures }\end{array}$ \\
\hline Nicolas Roehri & $\begin{array}{l}2 \text { Aix Marseille Univ, } \\
\text { Inserm, INS, Institut de Neurosciences } \\
\text { des Systèmes, Marseille }\end{array}$ & $\begin{array}{l}\text { conception and design of the study } \\
\text { analysed the data } \\
\text { drafted the manuscript and the figures }\end{array}$ \\
\hline Bernard Giusiano & $\begin{array}{l}2 \text { Aix Marseille Univ, } \\
\text { Inserm, INS, Institut de Neurosciences } \\
\text { des Systèmes, Marseille }\end{array}$ & $\begin{array}{l}\text { conception and design of the study } \\
\text { analysed the data }\end{array}$ \\
\hline Stanislas Lagarde & $\begin{array}{l}1 \text { Aix Marseille Univ, APHM, } \\
\text { INSERM, INS, Inst Neurosci Syst, } \\
\text { Timone Hospital, Epileptology } \\
\text { Department, Marseille, France }\end{array}$ & $\begin{array}{l}\text { conception and design of the study } \\
\text { acquired the data } \\
\text { analysed the data }\end{array}$ \\
\hline Romain Carron & $\begin{array}{l}3 \text { Aix Marseille Univ, APHM, } \\
\text { INSERM, INS, Inst Neurosci Syst, }\end{array}$ & $\begin{array}{l}\text { conception and design of the study } \\
\text { analysed the data }\end{array}$ \\
\hline
\end{tabular}




\begin{tabular}{|c|c|c|}
\hline & $\begin{array}{l}\text { Timone Hospital, Functional and } \\
\text { Stereotactic Neurosurgery, Marseille, } \\
\text { France }\end{array}$ & \\
\hline Didier Scavarda & $\begin{array}{l}4 \text { Aix Marseille Univ, APHM, } \\
\text { INSERM, INS, Inst Neurosci Syst, } \\
\text { Timone Hospital, } \quad \text { Pediatric } \\
\text { Neurosurgery, Marseille, France }\end{array}$ & $\begin{array}{l}\text { conception and design of the study } \\
\text { analysed the data }\end{array}$ \\
\hline Aileen McGonigal & $\begin{array}{l}\text { Aix Marseille Univ, APHM, } \\
\text { INSERM, INS, Inst Neurosci Syst, } \\
\text { Timone Hospital, Epileptology } \\
\text { Department, Marseille, France }\end{array}$ & \\
\hline Cristina Filipescu & $\begin{array}{l}5 \text { GHU Paris, Psychiatrie et } \\
\text { Neurosciences, St Anne, Paris }\end{array}$ & acquired the data \\
\hline Isabelle Lambert & $\begin{array}{l}\text { Aix Marseille Univ, APHM, } \\
\text { INSERM, INS, Inst Neurosci Syst, } \\
\text { Timone Hospital, Epileptology } \\
\text { Department, Marseille, France }\end{array}$ & $\begin{array}{l}\text { conception and design of the study } \\
\text { analysed the data }\end{array}$ \\
\hline Francesca Bonini & $\begin{array}{l}1 \text { Aix Marseille Univ, APHM, } \\
\text { INSERM, INS, Inst Neurosci Syst, } \\
\text { Timone Hospital, Epileptology } \\
\text { Department, Marseille, France }\end{array}$ & $\begin{array}{l}\text { conception and design of the study } \\
\text { analysed the data }\end{array}$ \\
\hline Agnes Trebuchon & $\begin{array}{l}1 \text { Aix Marseille Univ, APHM, } \\
\text { INSERM, INS, Inst Neurosci Syst, } \\
\text { Timone Hospital, Epileptology } \\
\text { Department, Marseille, France }\end{array}$ & $\begin{array}{l}\text { conception and design of the study } \\
\text { analysed the data }\end{array}$ \\
\hline $\begin{array}{l}\text { Christian - George } \\
\text { Bénar }\end{array}$ & $\begin{array}{l}2 \text { Aix Marseille Univ, } \\
\text { Inserm, INS, Institut de } \\
\text { des Systèmes, Marseille }\end{array}$ & $\begin{array}{l}\text { conception and design of the study } \\
\text { analysed the data } \\
\text { drafted the manuscript }\end{array}$ \\
\hline Fabrice Bartolomei & $\begin{array}{l}\text { Aix Marseille Univ, APHM, } \\
\text { INSERM, INS, Inst Neurosci Syst, } \\
\text { Timone Hospital, Epileptology } \\
\text { Department, Marseille, France }\end{array}$ & $\begin{array}{l}\text { conception and design of the study } \\
\text { analysed the data } \\
\text { drafted the manuscript }\end{array}$ \\
\hline
\end{tabular}




\section{References}

1. Broughton R, Gastaut H. Epileptic Seizures. 1972.

2. Jasper HH. Electrical signs of epileptic discharge. Electroencephalogr Clin Neurophysiol. Epub 1949.:11-18.

3. Rosenberg DS, Mauguière F, Demarquay G, et al. Involvement of medial pulvinar thalamic nucleus in human temporal lobe seizures. Epilepsia. 2006;47:98-107.

4. Guye M, Régis J, Tamura M, et al. The role of corticothalamic coupling in human temporal lobe epilepsy. Brain. 2006;129:1917-1928.

5. Yu T, Wang X, Li Y, et al. High-frequency stimulation of anterior nucleus of thalamus desynchronizes epileptic network in humans. Brain. 2018;141:2631-2643.

6. Evangelista E, Bénar C, Bonini F, et al. Does the thalamo-cortical synchrony play a role in seizure termination? Front Neurol. 2015;6.

7. Aupy J, Wendling F, Taylor K, Bulacio J, Gonzalez-martinez J, Chauvel P. Corticostriatal synchronization in human focal seizures. Brain. Epub 2019.:1-14.

8. Rektor I, Kuba R, Brázdil M. Interictal and ictal EEG activity in the basal ganglia: An SEEG study in patients with temporal lobe epilepsy. Epilepsia. 2002;43:253-262.

9. Sherdil A, Coizet V, Pernet-Gallay K, David O, Chabardès S, Piallat B. Implication of Anterior Nucleus of the Thalamus in Mesial Temporal Lobe Seizures. Neuroscience [online serial]. Elsevier Ltd on behalf of IBRO; Epub 2019. Accessed at: https://linkinghub.elsevier.com/retrieve/pii/S0306452219304245. 
10. Devergnas A, Piallat B, Prabhu S, et al. The subcortical hidden side of focal motor seizures: Evidence from micro-recordings and local field potentials. Brain. 2012;135:2263-2276.

11. Vuong J, Devergnas A. The role of the basal ganglia in the control of seizure. J Neural Transm. Springer Vienna; Epub 2017.

12. Keller SS, Richardson MP, Schoene-Bake JC, et al. Thalamotemporal alteration and postoperative seizures in temporal lobe epilepsy. Ann Neurol. 2015;77:760-774.

13. Whelan CD, Altmann A, Botía JA, et al. Structural brain abnormalities in the common epilepsies assessed in a worldwide ENIGMA study. Brain. 2018;141:391-408.

14. Rektor I, Tomčík J, Mikl M, Mareček R, Brázdil M, Rektorová I. Association between the basal ganglia and large-scale brain networks in epilepsy. Brain Topogr. 2013;26:355-362.

15. Morgan VL, Rogers BP, Abou-khalil B. Segmentation of the Thalamus Based on BOLD Frequencies affected in Temporal Lobe Epilepsy. 2016;56:1819-1827.

16. Chassoux F, Artiges E, Semah F, et al. Determinants of brain metabolism changes in mesial temporal lobe epilepsy. Epilepsia. 2016;57:907-919.

17. He X, Chaitanya G, Asma B, et al. Disrupted basal ganglia-thalamocortical loops in focal to bilateral tonic-clonic seizures. Brain. 2020;143:175-190.

18. He X, Doucet GE, Pustina D, Sperling MR, Sharan AD, Tracy JI. Presurgical thalamic "hubness" predicts surgical outcome in temporal lobe epilepsy. Neurology [online serial]. 2017;88:2285-2293. Accessed at: http://dx.doi.org/10.1212/WNL.0000000000004035. 
19. Výtvarová E, Mareček R, Fousek J, Strýček O, Rektor I. Large-scale corticosubcortical functional networks in focal epilepsies: The role of the basal ganglia. NeuroImage Clin. 2017;14:28-36.

20. Park KM, Lee BI, Shin KJ, et al. Pivotal Role of Subcortical Structures as a Network Hub in Focal Epilepsy : Evidence from Graph Theoretical Analysis Based on Diffusion-Tensor Imaging. 2019;15:68-76.

21. Fisher RS, Velasco AL. Electrical brain stimulation for epilepsy. Nat Rev Neurol [online serial]. Nature Publishing Group; 2014;10:261-270, Accessed at: http://dx.doi.org/10.1038/nrneurol.2014.59.

22. Medina Villalon S, Paz R, Roehri N, et al. EpiTools, A software suite for presurgical brain mapping in epilepsy: Intracerebral EEG. J Neurosci Methods. Elsevier B.V.; 2018;303:7-15.

23. Colombet B, Woodman M, Badier JM, Bénar C-G. AnyWave: A cross-platform and modular software for visualizing and processing electrophysiological signals. J Neurosci Methods. Elsevier B.V.; 2015;242:118-126.

24. Roehri N, Lina J, Mosher JC, Bartolomei F, Benar CG. Time-frequency strategies for increasing high frequency oscillation detectability in intracerebral EEG. 2016;2:1-12.

25. Lagarde S, Bonini F, McGonigal A, et al. Seizure-onset patterns in focal cortical dysplasia and neurodevelopmental tumors: Relationship with surgical prognosis and neuropathologic subtypes. Epilepsia. Epub 2016.:1-10.

26. Roehri N, Pizzo F, Lagarde S, et al. High-frequency oscillations are not better biomarkers of epileptogenic tissues than spikes. Ann Neurol. 2018;83:84-97. 
27. Bartolomei F, Chauvel P, Wendling F. Epileptogenicity of brain structures in human temporal lobe epilepsy: A quantified study from intracerebral EEG. Brain. 2008;131:1818-1830.

28. Benjamini Y, Hochberg Y. Controlling the False Discovery Rate: A Practical and Powerful Approach to Multiple Testing. J. R. Stat. Soc. 1995. p. 289-300.

29. Fay MP, Malinovsky Y. Confidence intervals of the Mann-Whitney parameter that are compatible with the Wilcoxon-Mann-Whitney test. Stat Med. 2018;37:3991-4006.

30. Behrens TEJ, Johansen-Berg H, Woolrich MW, et al. Non-invasive mapping of connections between human thalamus and cortex using diffusion imaging. Nat Neurosci. 2003;6:750-757.

31. Song Y, Jiaxiang Z. Discriminating preictal and interictal brain states in intracranial EEG.pdf. J. Neurosci. Methods 2016. p. 45-54

32. Jo HJ, Kenny-Jung DL, Balzekas I, et al. Nuclei-specific thalamic connectivity predicts seizure frequency in drug-resistant medial temporal lobe epilepsy. NeuroImage Clin [online serial]. Elsevier; 2019;21:101671. Accessed at: https://doi.org/10.1016/j,nicl.2019.101671.

33. Rosenberg DS, Mauguière F, Catenoix H, Faillenot I, Magnin M. Reciprocal thalamocortical connectivity of the medial pulvinar: A depth stimulation and evoked potential study in human brain. Cereb Cortex. 2009;19:1462-1473.

34. Ghaziri J, Tucholka A, Girard G, et al. The Corticocortical Structural Connectivity of the Human Insula. Cereb Cortex. 2017;27:1216-1228.

35. Sherman SM. Thalamic relays and cortical functioning. Prog Brain Res. 
2005;149:107-126.

36. Filipescu C, Lagarde S, Lambert I, et al. The effect of medial pulvinar stimulation on temporal lobe seizures. Epilepsia. Epub 2019.:1-6.

37. Kini LG, Bernabei JM, Mikhail F, et al. Virtual resection predicts surgical outcome for drug resistant epilepsy. Brain. Epub 2019.:1-14.

38. Rektor I, Kuba R, Brázdil M, Halámek J, Jurák P. Ictal and peri-ictal oscillations in the human basal ganglia in temporal lobe epilepsy. Epilepsy Behav [online serial]. Elsevier Inc.; 2011;20:512-517. Accessed at:

http://linkinghub.elsevier.com/retrieve/pii/S1525505011000059.

39. Dreifuss S, Vingerhoets FJG, Lazeyras F, et al. Volumetric measurements of subcortical nuclei in patients with temporal lobe epilepsy. Neurology. 2001;57:16361641.

40. Rektor I, Kuba R, Brázdil M, Chrastina J. Do the basal ganglia inhibit seizure activity in temporal lobe epilepsy? Epilepsy Behav [online serial]. Elsevier Inc.; 2012;25:5659. Accessed at: http://linkinghub.elsevier.com/retrieve/pii/S1525505012003332.

41. Cloppenborg T, May TW, Blümcke I, et al. Trends in epilepsy surgery: Stable surgical numbers despite increasing presurgical volumes. J Neurol Neurosurg Psychiatry. 2016;87:1322-1329.

42. Isnard J, Taussig D, Bartolomei F, et al. French guidelines on stereoelectroencephalography (SEEG). Neurophysiol Clin. Elsevier Masson SAS; Epub 2017.

43. Cossu M, Fuschillo D, Casaceli G, et al. Stereoelectroencephalography-guided 
radiofrequency thermocoagulation in the epileptogenic zone: a retrospective study on 89 cases. J Neurosurg. 2015;123:1358-1367.

44. Marchi A, Pennaroli D, Lagarde S, et al. Epileptogenicity and surgical outcome in post stroke drug resistant epilepsy in children and adults. Epilepsy Res. 2019;155:106155.

45. Neal A, Ostrowsky-Coste K, Jung J, et al. Epileptogenicity in tuberous sclerosis complex: A stereoelectroencephalographic study. Epilepsia. Epub 2019.:81-95.

46. Cuello Oderiz C, von Ellenrieder N, Dubeau F, et al. Association of Cortical Stimulation-Induced Seizure With Surgical Outcome in Patients With Focal DrugResistant Epilepsy. JAMA Neurol. Epub 2019.:1-9.

47. Bartolomei F, Lagarde S, Wendling F, et al. Defining epileptogenic networks : Contribution of SEEG and signal analysis. Epilepsia. Epub 2017.:1-17.

48. Malinowska U, Badier J, Gavaret M, Bartolomei F, Chauvel P, Bénar CG. Interictal Networks in Magnetoencephalography. Hum Brain Mapp. 2014;35:2789-2805.

49. An S, Bartolomei F, Guye M, Jirsa V. Optimization of surgical intervention outside the epileptogenic zone in the Virtual Epileptic Patient ( VEP ). PLoS Comput Biol 15(6). $2019 ; 15: 1-25$.

50. Olmi S, Petkoski S, Guye M, Bartolomei F, Jirsa V. Controlling seizure propagation in large-scale brain networks. PLoS Comput Biol. 2019;15:1-23. 